\title{
Relações entre uso do solo, relevo e fertilidade do solo em escala de microbacia
}

\author{
Antonio C. dos Santos ${ }^{1}$, Ignacio H. Salcedo 2 \& Sandra R. da S. Galvão 2
}

\section{RESU M O}

A produtividade em sistemas agrícolas de subsistência depende do nível de fertilidade natural do solo. Em condições de relevo forte ondulado, espera-se que a fertilidade do solo se modifique não apenas pelo tipo de uso mas, também, devido à sua posição no relevo. Para avaliar essas modificações, 260 amostras simples de solo $(0-20 \mathrm{~cm})$ da microbacia Vaca Brava, PB, representando combinações de três usos do solo, cinco posições no relevo e cinco classes texturais, foram analisadas quanto aos teores de $\mathrm{P}$ disponível, bases e acidez trocáveis. Ca e M g compreenderam $75-80 \%$ dos cátions trocáveis, $\mathrm{K}$ e Na, de 10 a 15\%, e H +Al, 10\%; o valor de pH médio foi 5,5, enquanto P M ehlich-1 foi, em média, 3,8 mg $\mathrm{kg}^{-1}$ solo. A pesar dos efeitos significativos $(p<0,05)$ de uso, relevo e textura nos teores de al guns nutrientes, de forma geral a bacia pareceu relativamente uniforme. A principal diferença entre os usos decorreu da adição de esterco em áreas de roçado e capineira localizadas, preferencialmente, em áreas de pedimento e várzea. Ao redor de $80 \%$ das amostras apresentaram teores baixos de $P$ enquanto 70\% mostraram teores médios de K; entretanto, utilizando-se o índice K/(Ca+ M g) $)^{0,5}$ conclui-se que a quase totalidade das amostras se apresentou deficiente em $\mathrm{K}$.

Palavras-chave: capineiras, agricultura de subsistência, pastagens, fósforo, potássio

\section{Relationships among land use, relief and soil fertility at watershed scale}

\begin{abstract}
Productivity in subsistence agricultural systems relies on natural soil fertility levels. Under strongly undulated relief conditions, it is expected that soil fertility will be determined not only by land use, but also by the position in the landscape. To study these relationships 260 single soil samples $(0-20 \mathrm{~cm})$ from the Vaca Brava watershed, Paraiba, representing combinations of three land uses, five positions in the landscape and five textures were analyzed for extractable $P$, exchangeable bases and soil acidity. $\mathrm{Ca}$ and $\mathrm{Mg}$ comprised $75-80 \%$ of exchangeable cations, $\mathrm{K}$ and $\mathrm{Na}$ between 10 and $15 \%$ and $\mathrm{H}+\mathrm{Al} 10 \%$. The average $\mathrm{pH}$ was 5.5, while extractable $\mathrm{P}$ (Mehlich-1) averaged $3.8 \mathrm{mg} \mathrm{kg}^{-1}$ soil. Although land use, relief and texture exerted significant effects $(p<0.05)$ upon certain nutrient concentrations, in a broad sense the watershed appeared relatively uniform. The main effect of land use resulted from the use of animal manure in areas of subsistence agriculture and fodder, which were preferentially located at the base of stopes and low lands positions. Approximately $80 \%$ of the samples were low in extractable $\mathrm{P}$, while $70 \%$ had medium level s of extractable $\mathrm{K}$. However, when available $\mathrm{K}$ was estimated by the $\mathrm{K} /(\mathrm{Ca}+\mathrm{Mg})^{0,5}$ ratio, most samples were classified as low.
\end{abstract}

Key words: fodder, subsistence agriculture, pasture, phosphorus, potassium

\footnotetext{
1 Universidade Federal do Tocantins. Campus de Araguaína - EMVZ. BR 153, Km 112, CP 132. CEP 77.804-970, Araguaína, TO. Fone (63) 414.1802. E-mail: clementino@uft.edu.br

2 Departamento de Energia Nuclear/U FPE, Av. Prof. Luiz Freire 1000. CEP 50740-540. Recife, PE. Fone (81) 2126-8252. E-mail: salcedo@ufpe.br; reginassg@hotmail.com
} 


\section{INTRODUÇÃO}

A exploração intensiva de áreas com agricultura ou pecuária familiar de subsistência, normalmente está associada à degradação do ambiente (Silva, 2000; Fraga \& Salcedo, 2004); esta degradação é representada pela perda de biodiversidade, pela queda na fertilidade do solo e pela intensificação dos processos erosivos em relação às condições encontradas sob vegetação original (Santos, 2004; Fraga \& Salcedo, 2004). Os solos utilizados para culturas anuais são, comumente, os que apresentam maior alteração em relação àqueles sob vegetação nativa (Tiessen et al., 1992; Alvarenga \& Davide, 1999; Fraga \& Salcedo, 2004).

O tipo de relevo afeta a redistribuição de água e sedimentos na paisagem que, por sua vez, influenciam o tipo de uso do solo. Em estudo realizado em bacia de relevo ondulado, determinou-se que $82 \%$ da área se constituíam de encostas, $15 \%$ de várzeas e 2\% de topos (Santos et al., 2002); de forma geral, é nessas duas últimas posições que se concentra a atividade agrícola de maneira mais permanente, por se tratar de áreas planas e com regime hídrico mais favorável, enquanto as encostas são, comumente, ocupadas por pastagens, após um curto ciclo agrícola inicial que se segue à derrubada da mata nativa (Santos et al., 2002; Bertoni \& Lombardi Neto, 1999).

É comum as pastagens sofrerem alta pressão de pastejo, o que deixa a superfície do solo exposta e vulnerável a processos erosivos, razão pela qual muitas vezes o horizonte B fica exposto à superfície (Santos et al., 2002; Fraga \& Salcedo, 2004). A maior parte dos sedimentos e nutrientes removidos das encostas é redistribuída para as várzeas, o que pode contribuir para aumentos na fertilidade dos solos dessas últimas (Galvão et al., 2005); entretanto, também há redistribuição de água e nutrientes das várzeas para as áreas com menor cota da bacia, ocupadas, em geral, por açudes ou barragens, o que representa perda líquida de nutrientes do sistema.

Há poucos estudos que integram o comportamento da fertilidade do solo com as distintas posições no relevo e usos do solo, em escala de microbacia. Galvão et al. (2005) determinaram os teores totais de $\mathrm{C}$ e $\mathrm{N}$ e de suas frações lábeis em amostras de solos provenientes de amostragem estratificada na microbacia de Vaca Brava, PB, caracterizando cada amostra quanto à posição no relevo, classe textural e uso da terra.

Objetivou-se, neste trabalho, determinar como essas três variáveis qualitativas influenciam nos teores de $\mathrm{P}$ extraível e de bases e acidez trocável, em escala de microbacia.

\section{MATERIAL E MÉTODOS}

O trabalho foi realizado na microbacia de Vaca Brava, localizada na microrregião do Brejo, na mesorregião do Agreste, contraposto oriental do Planalto da Borborema, do Estado da Paraíba, Nordeste do Brasil, compreendida entre as coordenadas (UTM) 192000 e 198000 m E e 9225300 e 9231000 m N. Segundo a classificação de Köppen, o clima é do tipo As' (tropical chuvoso) (Chaves, 1977). A microbacia ocupa uma superfície de 1500 ha, com altitude média de 637 m e temperatura média anual de $24{ }^{\circ} \mathrm{C}$ indicando pequena amplitude de variação (Santos et al., 2002). Os solos que predominam na bacia são uma associação de Argissolo Vermelho-Amarelo Eutrófico e Neossolo Litólico Eutrófico e, em menor proporção, o Neossolo Regolítico e o Latossolo Amarelo Distrófico (EMBRAPA, 1999).

A microbacia se localiza quase que inteiramente no município de Areia e apresenta clima tropical chuvoso (pluviosidade anual de $1.200 \mathrm{~mm}$ ) com chuvas de outono - inverno e déficit hídrico de setembro a janeiro, com relevo ondulado a fortemente ondulado. A parte da microbacia que se localiza no município de Remígio, PB, apresenta características edafoclimáticas de transição, com solos arenosos, relevo menos declivoso e marcante declínio na pluviosidade anual (820 mm) (Silva et al., 1993), com déficit hídrico de setembro a fevereiro; esta microbacia apresenta, ainda, dois tipos de uso da terra predominantes: uma área de reserva ecológica (mata nativa) e outra de agropecuária familiar. $\mathrm{Na}$ área sob influência antrópica, com uma área de aproximadamente 794 ha (Santos et al., 2002), se encontram, atualmente, cinco tipos de uso do solo: capoeira (área de pousio), sabiá (Mimosa caesalpiniaefolia), pastagem, capineira e roçado (agricultura de subsistência e baixa produtividade). A pastagem é o tipo de uso com maior área de abrangência em função da principal atividade econômica da região ser a pecuária; apenas os três últimos sistemas de uso foram abordados nesta pesquisa. A coleta de solo se baseou em um desenho estratificado de amostragem, com combinação fatorial incompleta de estratos, 5 x 3, isto é, cinco posições no relevo (topo, ombro, meia encosta, pedimento e várzea) e três sistemas de uso do solo (roçado, pastagem e capineira). A combinação foi incompleta visto que algumas situações de uso não foram encontradas nas cinco posições do relevo. $\mathrm{O}$ número de amostras em cada estrato se encontra na Tabela 1 . As posições no relevo deram origem a variações texturais marcantes, motivo pelo qual esta variável foi incorporada ao desenho experimental na análise dos dados.

Tabela 1. Número de amostras de solo obtidas por estrato na microbacia Vaca Brava, PB

\begin{tabular}{lccccrr}
\hline Uso do Solo & Várzea & \multicolumn{3}{c}{ Encosta } & & Meia \\
\cline { 3 - 5 } & & Pedimento & Ombro & Topo & Total \\
Roçado & 16 & 13 & 36 & 9 & 10 & 84 \\
Pastagem & 19 & 17 & 74 & 10 & 13 & 133 \\
Capineira & 16 & 6 & 19 & - & 2 & 43 \\
Total & 51 & 36 & 129 & 19 & 25 & 260 \\
\hline
\end{tabular}

Em cada ponto amostral geo-referenciado, retiraram-se e se misturaram amostras de solo da camada de $0-20 \mathrm{~cm}$ de vários pontos em área de 10 x $10 \mathrm{~m}$; uma vez que esta área amostral $\left(100 \mathrm{~m}^{2}\right)$ foi, pelo menos, duas ordens de magnitude menor que a área representada pela amostra, esta última foi considerada amostra simples; durante a amostragem, observou-se grau elevado de erosão nas encostas. 
As amostras foram secadas ao ar, passadas por peneira de $2 \mathrm{~mm}$ e analisadas quanto a granulometria, $\mathrm{pH}, \mathrm{Ca}$ e $\mathrm{Mg}$ trocáveis, acidez trocável e $\mathrm{P}, \mathrm{K}$ e Na extraíveis por Mehlich-1 (EMBRAPA, 1997) e C total (Snyder \& Trofymow, 1984).

As variáveis quantitativas apresentaram distribuição lognormal e por este motivo foram apresentadas médias geométricas (Parkin \& Robinson, 1993). Os atributos do solo foram avaliados, inicialmente, por meio de estatística descritiva: média geométrica, mediana, valores máximo e mínimo, e primeiro e terceiro quartis. Realizou-se a análise de variância (ANOVA) com as variáveis transformadas, utilizando-se um esquema fatorial incompleto $5 \times 3 \times 5$ (cinco posições no relevo, três sistemas de uso e cinco classes texturais) (SAS, 1985). As médias foram comparadas aplicando-se o teste de Tukey a nível de $5 \%$.

\section{RESULTADOS E DISCUSSÃO}

\section{Análise descritiva}

Os valores interquartílicos sumarizados na Tabela 2, independentemente da origem da amostra, evidenciam a assimetria das distribuições de freqüência dos atributos medidos. No caso do C total, por exemplo, metade das amostras apresentou teores entre 4,3 e $10,5 \mathrm{~g} \mathrm{~kg}^{-1}$ e a outra metade entre 10,5 e $34,2 \mathrm{~g} \mathrm{~kg}^{-1}$; assimetria maior correspondeu ao $\mathrm{P}$, com teores inferiores a $6,9 \mathrm{mg} \mathrm{kg}^{-1} \mathrm{em} 75 \%$ das amostras enquanto o teor em $25 \%$ delas ficou no intervalo $6,9-50 \mathrm{mg} \mathrm{kg}^{-1}$.

Tabela 2. Média geométrica (MG), valor mínimo (Min), quartil inferior (QI), mediana (Med), quartil superior (QS) e valor máximo (Max) dos atributos químicos das amostras de solo da microbacia Vaca Brava, PB $(n=260)$

\begin{tabular}{lrrrrrr}
\hline Atributos & MG & Min & Q & Med & QS & Max \\
\hline $\mathrm{C}$ total $\left(\mathrm{g} \mathrm{kg}^{-1}\right)$ & 10,7 & 4,31 & 8,35 & 10,5 & 13,8 & 34,3 \\
$\mathrm{pH}$ & 5,5 & 4,3 & 5,1 & 5,4 & 5,8 & 8,4 \\
$\mathrm{P}\left(\mathrm{mg} \mathrm{kg}^{-1}\right)$ & 3,8 & 0,43 & 1,8 & 3,3 & 6,9 & 50 \\
$\mathrm{Ca}\left(\mathrm{cmol}_{\mathrm{c}} \mathrm{kg}^{-1}\right)$ & 1,4 & 0,283 & 1,02 & 1,41 & 2,03 & 4,69 \\
$\mathrm{Mg}\left(\mathrm{cmol}_{\mathrm{c}} \mathrm{kg}^{-1}\right)$ & 0,82 & 0,19 & 0,52 & 0,83 & 1,2 & 4,5 \\
$\mathrm{~K}\left(\mathrm{mg} \mathrm{kg}^{-1}\right)^{*}$ & 55 & 3,9 & 38 & 57 & 83 & 320 \\
$\mathrm{Na}\left(\mathrm{mg} \mathrm{kg}^{-1}\right)$ & 10,4 & 0,46 & 4,4 & 8,7 & 25 & 224 \\
$\mathrm{H}+\mathrm{Al}\left(\mathrm{cmol}_{\mathrm{c} \mathrm{kg}}{ }^{-1}\right)$ & 0,14 & 0,00 & 0,05 & 0,10 & 0,24 & 2,9 \\
\hline
\end{tabular}

${ }^{*} \mathrm{~K}$ e Na foram determinados por extração com Mehlich-1

Para a maioria dos atributos, a distribuição foi log-normal, motivo pelo qual na Tabela 2 se indicaram as médias geométricas e não as aritméticas.

A maioria das amostras mostrou reação ácida (Tabela 2); apenas $25 \%$ delas permaneceram na faixa de 5,78 a 8,40 , sendo que, destas, unicamente quatro amostras tiveram $\mathrm{pH}$ e" 7; por outro lado, 50\% apresentaram pH inferior a 5,4 e se poderiam beneficiar da calagem, particularmente aquelas com pH no intervalo do primeiro quartil (Tabela 2); a maioria das amostras indicou valores baixos de acidez trocável $(\mathrm{H}+\mathrm{Al})$, quando comparados com os teores de $\mathrm{Ca}+\mathrm{Mg}$ (< $10 \%$ ); aproximadamente $80 \%$ da CTC corresponderam a Ca e $\mathrm{Mg}$, $\mathrm{K}$ e Na perfizeram 10 a $15 \%$, e $\mathrm{H}+\mathrm{Al}$ os $5-10 \%$ res- tante. Os valores de K e Na não foram apresentados em unidades de carga trocável, em razão de terem sido extraídos por Mehlich-1.

Não houve interação $(\mathrm{p}<0,05)$ entre uso do solo, posição no relevo e textura nos valores dos atributos de solo quantificados, motivo pelo qual os resultados foram discutidos com base no efeito principal de cada variável qualitativa.

\section{Efeito do uso do solo}

O tipo de uso do solo afetou as variáveis estudadas, com exceção do $\mathrm{pH}$ e da acidez trocável. O teor médio de $\mathrm{P}$ nas amostras das áreas de roçado $\left(6,3 \mathrm{mg} \mathrm{kg}^{-1}\right)$ e capineira $(5,5$ $\left.\mathrm{mg} \mathrm{kg}^{-1}\right)$ foi maior $(\mathrm{p}<0,05)$ que nas áreas sob pastagem $\left(2,5 \mathrm{mg} \mathrm{kg}^{-1}\right)$ (Tabela 3$)$.

Tabela 3. Teores médios de atributos das amostras de solo agrupadas por uso do solo, posição no relevo ou classe textural

\begin{tabular}{|c|c|c|c|c|c|c|c|}
\hline \multirow{2}{*}{$\begin{array}{l}\text { Critérios de } \\
\text { classificação } \\
\text { das amostras }\end{array}$} & \multirow[b]{2}{*}{$\mathrm{pH}$} & $\mathbf{P}$ & $K$ & $\mathrm{Na}$ & $\mathrm{Ca}$ & $\mathrm{Mg}$ & $\mathrm{H}+\mathrm{Al}$ \\
\hline & & \multicolumn{3}{|c|}{$\left(\mathrm{mg} \mathrm{kg}^{-1}\right)$} & \multicolumn{3}{|c|}{$\left(\mathrm{cmol}_{\mathrm{c}} \mathrm{kg}^{-1}\right)$} \\
\hline \multicolumn{8}{|c|}{ Uso do solo } \\
\hline Capineira ( $n=43$ ) & $5,6 \mathrm{a}$ & $5,5 \mathrm{a}$ & $43 b$ & $14 a$ & $1,6 \mathrm{a}$ & $1,01 \mathrm{a}$ & $0,16 \mathrm{a}$ \\
\hline Pastagem ( & $5,4 a$ & $2,5 b$ & $62 a$ & $11 a b$ & $1,2 b$ & $0,71 b$ & $0,14 a$ \\
\hline loçado & $5,6 a$ & $6,3 a$ & $51 a b$ & $8,7 b$ & $1,8 \mathrm{a}$ & $0,92 a$ & $0,13 a$ \\
\hline \multicolumn{8}{|c|}{ Posição no relevo } \\
\hline Topo $(n=25)$ & $5,5 \mathrm{ab}$ & $3,7 b c$ & $62 a$ & $6,2 b$ & $1,4 \mathrm{a}$ & $0,71 b$ & $0,14 a$ \\
\hline Ombro $(n=19)$ & $5,3 \mathrm{ab}$ & $2,3 c$ & $55 a$ & $5,1 b$ & $1,6 \mathrm{a}$ & $0,86 a b$ & $0,18 \mathrm{a}$ \\
\hline Meia Encosta $(n=129)$ & $5,5 \mathrm{ab}$ & $2,9 b c$ & $55 a$ & $8,5 b$ & $1,4 a$ & $0,79 b$ & $0,16 \mathrm{a}$ \\
\hline Pedimento $(n=36)$ & $5,7 a$ & $4,9 a b$ & $43 a$ & $6,0 \mathrm{~b}$ & $1,4 \mathrm{a}$ & $0,65 b$ & $0,10 a$ \\
\hline \multicolumn{8}{|c|}{ Classe textural } \\
\hline $\operatorname{Arg}(n=06)$ & 5,0 & 1,4 & 109 & 12 & 1,3 & 1,40 & 0,45 \\
\hline $\operatorname{Arg} \operatorname{Ar}(n=18)$ & $4,9 \mathrm{C}$ & $2,4 b c$ & $82 a$ & $8,7 a b$ & $1,3 a b$ & $0,93 \mathrm{ab}$ & $0,20 a$ \\
\hline $\operatorname{FrArgAr}(n=59)$ & $5,4 b$ & $2,5 \mathrm{c}$ & $62 a$ & $11 \mathrm{a}$ & $1,6 \mathrm{a}$ & $0,94 a$ & $0,17 \mathrm{a}$ \\
\hline $\operatorname{FrAr}(n=99)$ & $5,5 b$ & $4,2 a b$ & $47 a$ & $14 \mathrm{a}$ & $1,5 \mathrm{a}$ & $0,82 \mathrm{ab}$ & $0,12 a$ \\
\hline $\operatorname{ArFr}(n=78)$ & $5,7 a$ & $5,7 a$ & $51 \mathrm{a}$ & $5,9 b$ & $1,2 b$ & $0,68 \mathrm{~b}$ & $0,13 a$ \\
\hline
\end{tabular}

Letras iguais na coluna dentro de cada critério de classificação não diferem entre si a nível de $5 \%$ de probabilidade pelo teste de Tukey

De forma geral, os teores de P extraível encontrados nas três formas de uso da terra, foram baixos e atestam sua deficiência generalizada nos solos da região (Sampaio et al., 1995). $\mathrm{O}$ efeito do uso do solo nos teores de $\mathrm{Ca}, \mathrm{Mg}$ e $\mathrm{Na}$ foi semelhante ao do P, com maiores $(\mathrm{p}<0,05)$ teores nas amostras de capineira e roçado e menores na pastagem (Tabela 3 ). A pequena vantagem das áreas de roçado e capineira em relação às áreas com pastagem, decorreu de aplicações de esterco relativamente rotineiras naqueles dois sistemas de uso. Aumentos nos teores de nutrientes, como resultado da aplicação continuada de esterco, têm sido observados em outros trabalhos (Silva, 2004; Sharpley et al., 2004). As áreas com pastagens, por outro lado, não receberam nenhuma aplicação de adubo ou fertilizante, exceto pelas excretas dos animais no pasto.

De forma oposta ao $\mathrm{Ca}$ e $\mathrm{Mg}$, o teor de $\mathrm{K}$ trocável foi menor $(\mathrm{p}<0,05)$ nas amostras de solo das áreas de capineira; é possível que este fato seja resultado do desbalanço entre a elevada retirada de K pelo capim elefante (Pennisetum purpureum Schum.) que, no brejo paraibano, pode atingir produ- 
tividade anual de $25 \mathrm{Mg} \mathrm{ha}^{-1}$ de matéria seca (Queiroz Filho et al., 2000), e o menor aporte deste elemento pelo esterco. Normalmente, as áreas de capineira são localizadas em posições de maior disponibilidade de água, determinando uma produtividade de forragem bem maior que a das pastagens. A produtividade do capim elefante mencionada, combinada com um teor de $\mathrm{K}$ de $15 \mathrm{~g} \mathrm{~kg}^{-1}$ na matéria seca (Andrade et al., 2000) representa uma retirada anual de $\mathrm{K}$ de $375 \mathrm{~kg} \mathrm{ha}^{-1}$; embora o teor de $\mathrm{K}$ no esterco seja bastante variável, se pode, para fins de estimativa, utilizar o valor encontrado por Holanda (1990), de $11 \mathrm{~g} \mathrm{~kg}^{-1}$; assumindo-se uma dose média de esterco na região de $7 \mathrm{Mg} \mathrm{ha}^{-1}$ (matéria seca), resulta um aporte de $77 \mathrm{~kg} \mathrm{ha}^{-1}$, ou seja, ao redor de $20 \%$ da retirada. O desbalanço entre aportes e retiradas resulta em um empobrecimento em $\mathrm{K}$ das áreas sob capineira mais marcante que nos outros dois usos do solo.

Embora estatisticamente significativas, as diferenças na fertilidade do solo entre os distintos usos da terra foram relativamente pequenas e, de forma geral, os teores de nutrientes se apresentaram baixos, o que caracteriza o predomínio de uma agropecuária de subsistência, na qual não se utilizam fertilizantes comerciais e os teores dos elementos no solo dependem dos níveis de fertilidade natural, da adubação orgânica, da ciclagem de nutrientes e da redistribuição de sedimentos e nutrientes devido aos processos erosivos (Sampaio et al., 1995; Tiessen et al., 1998).

\section{Efeito da Posição no Relevo}

De forma geral, foi notável a relativa uniformidade dos teores de $\mathrm{Ca}, \mathrm{K}$ e $\mathrm{H}+\mathrm{Al}$ nas amostras de solo quando classificadas pela posição no relevo (Tabela 3); quanto ao P, Mg e $\mathrm{Na}$, as amostras das várzeas apresentaram teores maiores ( $\mathrm{p}$ $<0,05$ ) que os das encostas (ombro, meia encosta e pedimento) (Tabela 3). Os maiores teores nas várzeas (e no pedimento para o P) decorreram, provavelmente, da preferência dos agricultores por esta posição do relevo para uso agrícola.

Nas posições de pedimento e várzea predominaram texturas mais grossas (Tabela 3) (Galvão et al., 2005), mais favoráveis para o cultivo manual e onde, também, ocorre maior acúmulo de água, permanecendo úmidas durante períodos mais longos. As aplicações de esterco nas áreas de roçado e capineira, já mencionadas, justificariam os maiores teores de $\mathrm{P}$ e de $\mathrm{Mg}$; o Na foi o íon que mais se acumulou nas várzeas, apresentando concentração cinco vezes maior que nas demais posições (Tabela 3); é provável que isto não reflita a aplicação local de esterco e, sim, os aportes contínuos de $\mathrm{Na}$ via urina animal nas encostas, onde predominam as pastagens, associados ao fato do Na ser o íon trocável retido com menor energia pelo complexo sortivo (McBride, 1994), o que contribui para que seja mais facilmente lavado. As encostas ocupam $82 \%$ da área da bacia enquanto as várzeas, somente $15 \%$ (Santos et al., 2002), o que explicaria o fator de aumento na concentração de $\mathrm{Na}$ entre essas duas posições no relevo.

A redistribuição de água e sedimentos em áreas de relevo ondulado ou forte ondulado, é prevista e, no caso específico da microbacia de Vaca Brava, PB, a erosão foi avaliada em três topossequiências pela técnica do ${ }^{137} \mathrm{Cs}$ (Santos, 2004), cujos resultados indicaram perdas de $20 \mathrm{~cm}$ de solo na posi- ção do ombro e de $25 \mathrm{~cm}$ na meia encosta, em relação à posição de topo; esta redistribuição de sedimentos afetou a proporção de amostras das três classes texturais mais relevantes, em relação à posição no relevo (Tabela 4).

Tabela 4. Número de amostras por classe textural e posição do relevo

\begin{tabular}{lccc}
\hline Posição & ArFr & FrAr & FrArgAr \\
\hline Topo & 7 & 8 & 6 \\
Ombro & 7 & 2 & 8 \\
Meia encosta & 25 & 49 & 37 \\
Pedimento & 17 & 15 & 4 \\
Várzea & 22 & 25 & 4 \\
\hline
\end{tabular}

O predomínio relativo de amostras FrArgAr na posição de meia encosta (Tabela 4) decorre, provavelmente, de ter sido amostrada, nesta posição, uma camada de solo que incluiu parte do horizonte B do Argissolo.

A semelhança nas concentrações dos nutrientes nas posições de topo e encosta (ombro e meia encosta), apesar da perda de solo sofrida pelas encostas (Santos, 2004), indica que a distribuição vertical de nutrientes nos primeiros $40 \mathrm{~cm}$ de solo no topo e encosta, deva ter sido relativamente uniforme, haja vista que a camada amostrada das encostas erodidas $(0-20 \mathrm{~cm})$ correspondeu, na realidade, à camada de 20$40 \mathrm{~cm}$ do perfil na posição de topo, não erodido; desta forma e pelos resultados obtidos no presente trabalho, os processos erosivos não parecem ter afetado os teores de $\mathrm{P}, \mathrm{Ca}, \mathrm{Mg}$ e $\mathrm{K}$ presentes no solo; resultados semelhantes foram observados por Galvão et al. (2005) em relação aos teores totais e de frações de C e $\mathrm{N}$ do solo. Não é possível concluir que, tampouco, houve mudanças nos estoques de nutrientes no solo porque haveria, também, necessidade de quantificá-los, pelo menos até um metro de profundidade; além da fertilidade do solo há, também, necessidade de se avaliar o efeito da erosão nas propriedades físicas. Em trabalho anterior se notou diminuição no teor de areia com o aumento da declividade (Santos et al., 2002); entretanto, há outras variáveis físicas, como compactação superficial e subsuperficial, infiltração e classes de porosidade, que afetam o desenvolvimento vegetal e não têm sido quantificadas ainda no contexto dos processos erosivos, em escala de microbacia.

\section{Efeito da classe textural}

$\mathrm{Na}$ área de estudo foram encontradas cinco classes texturais (Tabela 3), sendo as classes mais freqüentes areia-franca e franco-arenosa (Santos et al., 2002); aqui, a textura argilosa não foi considerada para a análise de variância devido ao reduzido número de amostras nessa classe textural (Tabela 3).

Dentre as três variáveis classificatórias estudadas, a textura foi a que mais influenciou na variação dos atributos químicos. O teor médio de P Mehlich-1 foi maior $(\mathrm{p}<0,05)$ nas amostras de textura média a grossa ( $\mathrm{ArFr}$ e FrAr) que nas de textura mais fina (FrArgAr e ArgAr) (Tabela 4); entretanto, todos os teores se apresentaram na faixa de deficiência de P. Como ressaltado antes, essas texturas foram mais 
frequientes nas posições de pedimento (grossa) e várzeas (média) (Tabela 3), nas quais predominam as capineiras e roçados, que receberam aportes de esterco. É provável que o maior valor de $\mathrm{pH}$ encontrado nas amostras de textura mais grossa (Tabela 3), que coincide com $\mathrm{pH}$ mais elevados em capineiras e roçados (Tabela 3 ) decorra também desses aportes de esterco (Cassol et al., 2001).

Para o Mg, $\mathrm{K}$ e acidez trocável, a tendência geral foi de aumento da concentração com o aumento do teor de argila na classe textural, embora poucos tenham sido significativos $(\mathrm{p}<0,05)$ (Tabela 3). O sódio e o Ca, por sua vez, não acompanharam essa tendência que era esperada, por conta da relação entre capacidade de troca de cátions e teor de argila (McBride, 1994); neste caso, os maiores teores foram observadas nas classes FrAr e FrArgAr (Tabela 3). A classe FrAr foi relativamente freqüente nas várzeas (Tabela 4), o que poderia justificar parcialmente a tendência observada.

A.

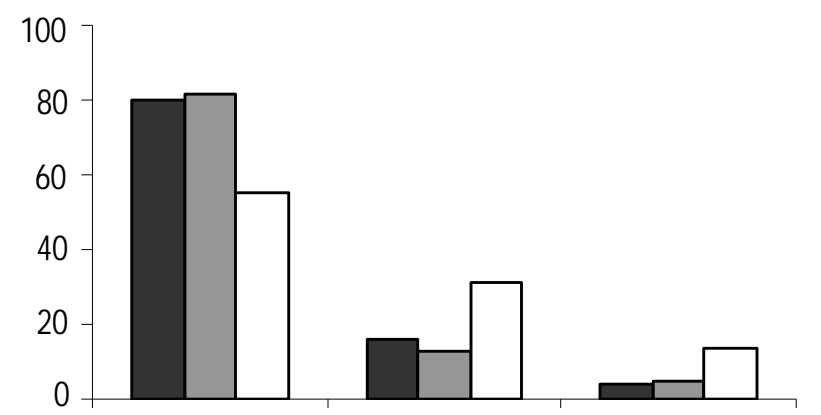

c.

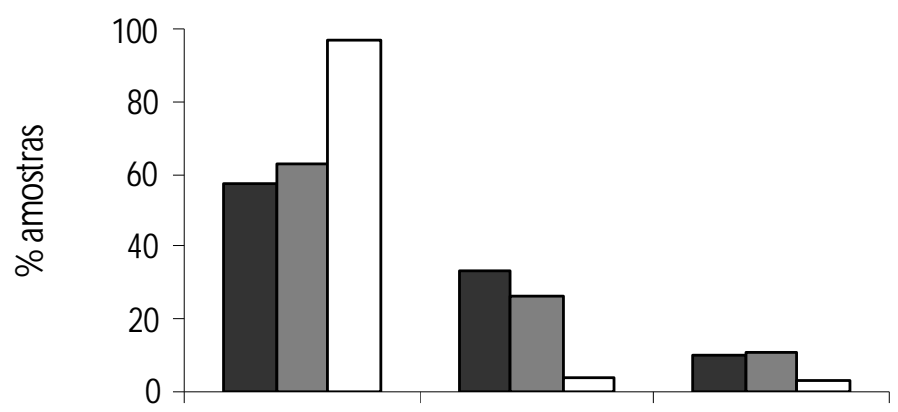

E.

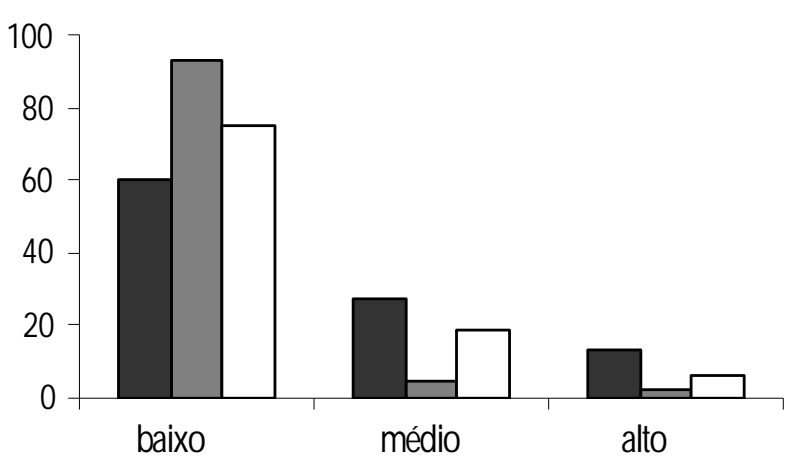

\section{Níveis de fertilidade do solo}

Para classificar as amostras quanto aos teores de $\mathrm{P}$ e de $\mathrm{K}$, utilizaram-se três faixas (baixa, média e alta); para o $\mathrm{P}$, essas faixas foram $0-10,11-20 \mathrm{e}>20 \mathrm{mg} \mathrm{dm}^{-3} \mathrm{e}$, para o $\mathrm{K}$, de 0 - 45, 46 - 90 e > $90 \mathrm{mg} \mathrm{dm}^{-3}$ (EMATER, 1979). Como as análises foram realizadas com base na massa das amostras, os valores das faixas foram mudados para massa de solo adotando-se uma densidade de solo média de $1,23 \mathrm{~kg} \mathrm{dm}^{-3}$ (Santos, 2004); então, as faixas para o P foram 0 - 8,1, 8,2 16,2 , e $>16,2 \mathrm{mg} \mathrm{kg}^{-1}$ enquanto para $\mathrm{K}$ foram $0-0,94,0,95$ $-1,88$, e $>1,88 \mathrm{mg} \mathrm{kg}^{-1}$.

As percentagens de amostras em cada uma dessas classes, em função da posição no relevo, do uso do solo e das classes texturais (unicamente as três mais representativas), estão resumidas na Figura 1; em relação ao P, notou-se predominância de amostras com baixos níveis desse nutriente, independentemente da variável classificatória (Figura 1a, c, d). Considerando-se unicamente as amostras com baixos ní-

B.

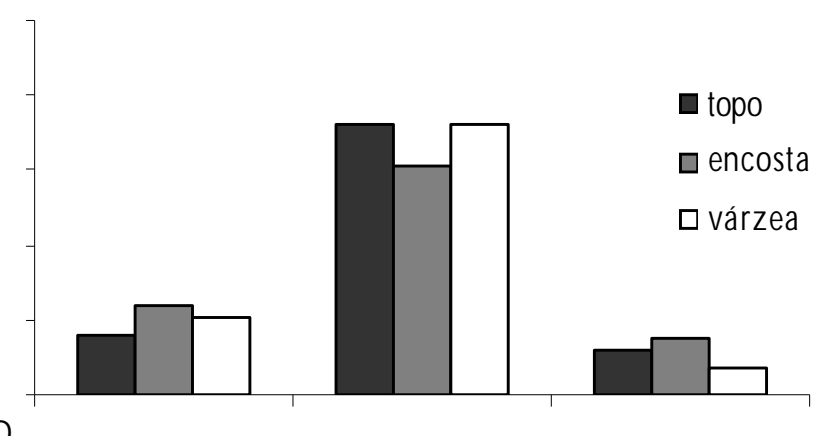

D.

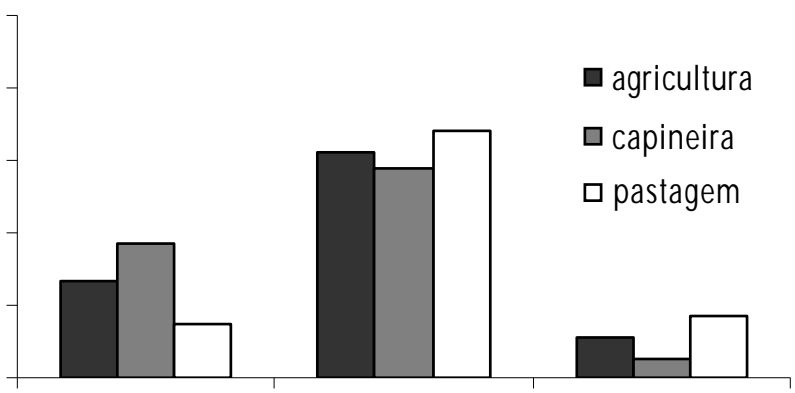

F.

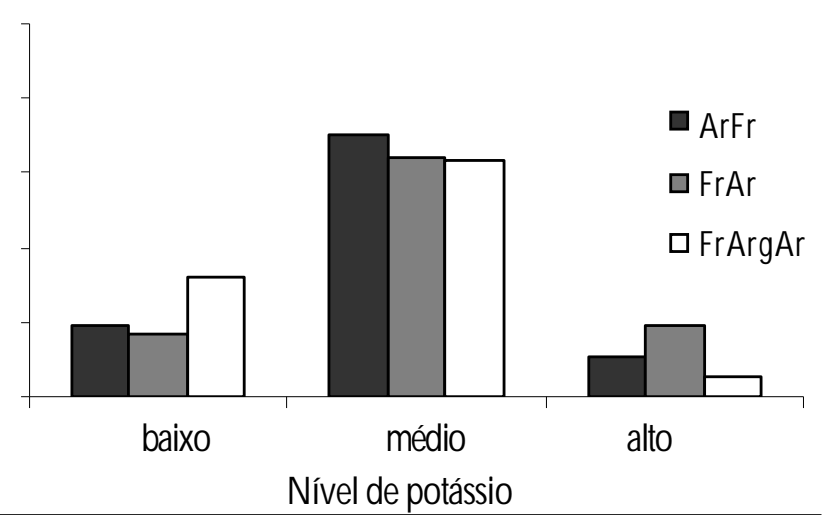

Figura 1. Percentagem de amostras de solo atribuída aos níveis baixo, médio e alto quanto aos teores de $P$ e K extraíveis por M ehlich-1, segundo as posições no relevo $(A, B)$, uso do solo $(C, D)$ e classe textural $(E, F)$ 
veis, conclui-se que sua menor percentagem ocorreu nas várzeas; em relação ao uso, ocorreu nas áreas com agricultura e capineira e, quanto à classe textural, ocorreu nas amostras ArFr, freqüentes nas áreas de várzea e pedimento. A menor proporção de amostras com baixos teores de $\mathrm{P}$ nessa combinação de relevo-uso-textura, reflete a adubação orgânica utilizada pelos agricultores já mencionada. Fica claro a necessidade de maiores pesquisas no tema de fertilização fosfatada, sobretudo em pastagens da região, mas também nas áreas de capineira e roçado.

Em referência ao $\mathrm{K}$, predominaram amostras com teores médios desse nutriente, com percentagens semelhantes, independentemente do nível das variáveis classificatórias (em todos os casos entre 60-70\% das amostras); é provável que a situação geral da fertilidade potássica seja pior da que se deriva desses resultados. A definição da fertilidade potássica baseada no teor de K trocável ou do extraído por outros extratores (Mehlich-1 neste caso) tem sido revisada criticamente (Castro \& Meneghelli, 1989); estes avaliaram a reposta à adubação potássica de numerosos ensaios realizados no País, utilizando um critério de fertilidade potássica relativa, representada pela relação $\mathrm{K} /(\mathrm{Ca}+\mathrm{Mg})^{0,5}$ (Beckett, 1964); para uma relação de 0,13 , a probabilidade de resposta ou não resposta à adubação potássica foi igual a 50\%; para índices menores, a probabilidade de resposta aumentou rapidamente $(0,10=$ $70 \%$; $0,084=80 \%$ e $0,059=90 \%$ ); este critério relativo também foi utilizado para cana-de-açúcar (Reis Júnior, 2001). Aplicando-se a mencionada relação às amostras de microbacia, metade daquelas retiradas das pastagens apresentou relação menor que 0,13 , enquanto $80 \%$ daquelas provenientes dos roçados e $100 \%$ oriundos das capineiras, apresentaram relação bastante menor que 0,13 ; assim e se utilizando este critério de fertilidade relativa, conclui-se que a situação de baixa disponibilidade de potássio ficou comparável à do fósforo.

\section{CONCLUSÕES}

1. O uso do solo, a posição no relevo e a textura, influenciaram significativamente $(\mathrm{p}<0,05)$ alguns dos atributos estudados mas, de forma geral, o nível de fertilidade dos solos da bacia pareceu relativamente uniforme.

2. O efeito mais claro, sobretudo no aumento do teor de $\mathbf{P}$ extraível, resultou das adições de esterco em áreas de roçado e de capineira, que coincidem com as áreas baixas do relevo e com texturas mais grossas.

3. A maioria das amostras da microbacia apresentou-se deficiente em $\mathrm{P}$ e $\mathrm{K}$ disponíveis.

\section{AGRADECIMENTOS}

Os autores agradecem ao Inter American Institute for Global Change (IAI) e ao Conselho Nacional de Desenvolvimento Científico e Tecnológico (CNPq) - Projeto Agricultura familiar, os recursos recebidos para execução deste trabalho; ao Centro de Ciências Agrárias-DSER/UFPB e ao Laborató- rio de Radiagronomia-DEN/UFPE e seus funcionários, pela disponibilização dos Laboratórios para análise de solos e também aos produtores da Microbacia Vaca Brava, por permitirem o acesso às propriedades e apoio, o que tornou possível esta pesquisa.

\section{LITERATURA CITADA}

Alvarenga, M. I. N.; Davide, A. C. Características físicas e químicas de um Latossolo Vermelho-Escuro e a sustentabilidade de agroecossistemas. Revista Brasileira Ciência do Solo, v.23, n.4, p.933-942, 1999.

Andrade, A. C.; Fonseca, D. M.; Gomide, J. A; Alvarez V. H.; Martins, C. E.; Souza, D. P. H. Produtividade e valor nutritivo do capim-elefante cv. Napier sob doses crescentes de nitrogênio e potássio. Revista Brasileira de Zootecnia, v.29, n.6, p.1589-1595, 2000.

Beckett, P. H. T. Studies on soil potassium. I. Confirmation of the ratio law: measurement of potassium potential. Journal of Soil Science, v.15, n.1, p.1-8, 1964.

Bertoni, J.; Lombardi Neto, F. Conservação do solo. São Paulo: Ícone, 1999. 335p.

Cassol, P. C.; Gianello, C.; Costa, V. E. U. Frações de fósforo em estrumes e sua eficiência como adubo fosfatado. Revista Brasileira de Ciência Solo, v.25, n.4, p.635-644, 2001.

Castro, A. F.; Meneghelli, N. A. As relações $\mathrm{K} /(\mathrm{Ca}+\mathrm{Mg})^{1 / 2} \mathrm{e}$ $\mathrm{K} /(\mathrm{Ca}+\mathrm{Mg})$ no solo e as respostas a adubação potássica. Pesquisa Agropecuária Brasileira, v.24, n.6, p.751-760, 1989.

Chaves, I. B. Erosividade das chuvas da microrregião homogênea n.98 - Estado da Paraíba. Piracicaba: ESALQ, 1977. 78p. Dissertação Mestrado

EMATER - Empresa de Assistência Técnica e Extensão Rural. Manual de sugestão de adubação para o Estado da Paraíba. Primeira aproximação. João Pessoa: EMATER, 1979. 105p.

EMBRAPA - Empresa Brasileira de Pesquisa Agropecuária. Manual de Métodos de análises de solos. 2.ed. Rio de Janeiro: Embrapa Solos, 1997. 212p.

EMBRAPA - Empresa Brasileira de Pesquisa Agropecuária. Sistema brasileiro de classificação de solos. Rio de Janeiro: Embrapa Solos, 1999. 412p.

Fraga, V. S.; Salcedo, I. H. Declines of organic nutrient pools in tropical semi-arid soils under subsystems farming. Soil Science Society of America Journal, v.68, n.1, p.215-224, 2004.

Galvão, S. R. S.; Salcedo, I. H.; Santos, A. C. Frações de carbono e nitrogênio em função da textura, do relevo e do uso do solo na microbacia do agreste em Vaca Brava (PB). Revista Brasileira de Ciência do Solo, v.29, n.4, p.955-962, 2005.

Holanda J. S. Esterco de curral: composição preservação e adubação. 17. Natal: EMPARN, 1990. 69p. Boletim Técnico

McBride, M. B. Environmental chemistry of soils. Oxford: Oxford University Press, 1994. 406p.

Parkin, T. B.; Robinson, J. A. Statistical evaluation of median estimators for lognormally distributed variables. Soil Science Society of America Journal, v.57, n.1, p.317-323, 1993.

Queiroz Filho, J. L.; Silva, D. S; Nascimento, I. S. Produção de matéria seca e qualidade do capim-elefante (Pennisetum purpureum Schum.) cultivar Roxo em diferentes idades de corte. Revista Brasileira de Zootecnia, v.29, n.1, p.69-74, 2000. 
Reis Júnior, R. A. Probabilidade de resposta da cana-de-açúcar à adubação potássica em razão da relação $\mathrm{K} /(\mathrm{Ca}+\mathrm{Mg})^{-}$ ${ }^{05}$ do solo. Pesquisa Agropecuária Brasileira, v.36, n.9, p.1175-1183, 2001.

Sampaio, E. V. S. B.; Salcedo, I. H.; Silva, F. B. R. Fertilidade de solos do semi-árido do nordeste. In: Fertilizantes: Insumo básico para agricultura e combate à fome. Petrolina, Embrapa CPATSA - SBCS, 1995. p.51-72.

Santos, A. C. Fertilidade do solo e redistribuição de ${ }^{137} \mathrm{Cs}$ em função da cobertura vegetal, relevo e classes texturais, em uma microbacia hidrográfica do estado da Paraíba. Recife: UFPE, 2004. 67p. Tese Doutorado

Santos, A. C.; Salcedo, I. H.; Candeias, A. L. B. Relação entre o relevo e as classes texturais do solo na microbacia hidrográfica de Vaca Brava, PB. Revista Brasileira de Cartografia, v.54, n.1, p.86-94, 2002.

SAS. User guide: Statistics. $5^{\text {th }}$ ed. Cary, NC: SAS Institute, 1985. 483p.

Sharpley, A. N.; McDowell, R. W.; Kleinman, P. J. A. Amounts, forms, and solubility of phosphorus in soils receiving manure. Soil Science Society of America Journal, v.68, n.6, p.2048-2057, 2004.
Silva, F. B. R.; Riché, G R.; Tonneau, J. P.; Sousa Neto, N. C.; Brito, L. T. L.; Correia, R. C.; Cavalcanti, A. C.; Silva, F. H. B. B.; Silva, A. B.; Araújo Filho, J. C.; Leite, A. P. Zoneamento agroecológico do Nordeste: Diagnóstico do quadro natural e agrossocioeconômico. Documentos, 80, v.2, Petrolina: Embrapa CPATSA, Recife: Embrapa CNPS, 1993. 387p.

Silva, J. R. C. Erosão e produtividade do solo no semi-árido. In: Oliveira, T. S.; Assis Jr., R. N.; Romero, R. E.; Silva, J. R. C, (ed.), Agricultura, sustentabilidade e o semi-árido. Fortaleza: UFC, 2000, cap.10, p.170-213.

Silva, T. O. Adubação orgânica da batata (Solanum tuberosum L.) com esterco e/ou Crotalaria juncea L. em um Neossolo Regolítico. Recife: UFPE, 2004, 47p. Dissertação Mestrado

Snyder, J. D.; Trofymow, J. A. A rapid accurate wet oxidation diffusion procedure for determining organic and inorganic carbon in plant and soil samples. Communications in Soil Science and Plant Analysis, v.15, n.5, p.587-597, 1984.

Tiessen, H; Cuevas, E.; Salcedo, I. H. Organic matter stability and nutrient availability under temperate and tropical conditions. Advances in GeoEcology, v.31, n.1, p.415-422, 1998.

Tiessen, H.; Salcedo, I. H.; Sampaio, E. V. S. B. Nutrient and soil organic matter dynamics under shifting cultivation in semi-arid northeastern Brazil. Agriculture, Ecosystems and Environment, v.38, n.3, p.139-151, 1992. 